\title{
Neither Here nor There: The Experiences of Zimbabwean Migrant Children and Youth
}

\author{
Sophia Chirongoma \\ ORCID iD: https://orcid.org/0000-0002-8655-7365
}

\begin{abstract}
This article is an auto-ethnographic exploration of how migration presents numerous adjustment challenges for Zimbabwean migrant children and youth. The author presents an auto-ethnographic account of how her son Tadiwanashe had to contend with numerous life-changing experiences throughout the migration path. The article illuminates the various ways in which children and youth who have migrated from Zimbabwe with their parents in search of greener pastures often find themselves struggling with an identity crisis. Hence, they find themselves neither belonging in the diaspora nor in their motherland. This puts them in a quagmire whereby they feel as if they are 'neither here nor there'. The article also foregrounds the various coping and survival strategies adopted by the migrant children and youth as they navigate their new spaces. It takes note of how they exercise their agency, resilience and creativity as they grapple with the changes thrust upon them due to parental migration. In concluding, the article reiterates the need for academic researchers to pay particular attention to the fact that children and youth should not be perceived as passive participants during the migration process, rather, their voices also deserve to be heard.
\end{abstract}

Keywords: coping and survival strategies, migrant children and youth, motherland, Zimbabwe

\section{Introduction and Self-Location}

This paper is written from the perspective of an insider-outsider. This is so because whilst I never migrated to a foreign country when I was still a child, I 
have glimpsed the life-changing experience of moving away from all that is familiar into an unfamiliar territory, experiences which I encountered at various phases of my life (Chirongoma 2012). Firstly, at the age of five, my parents decided to move our family from our 'comfort zone', a place I had come to call home to a completely new and unfamiliar place. Little did I realise that the place which I had grown to love to which I had become attached as my safety haven was only the 'teachers' quarters/residence' which is an accommodation facility allocated to teachers at most Zimbabwean school premises. When my father, who was a teacher transferred to another school near to our communal rural home, the move into this new territory did not augur well with me. Whilst my parents were enthused about finally resettling in our family's rural home, unfortunately for me, I had no absolute attachment to it, since we rarely used to visit our rural home before permanently moving there. As such, in my five-year-old worldview, moving there was an abrupt and nerve wrecking process. I had to start making new friends and adjust to the rural village lifestyle which was all too different from the cushioned and periurban lifestyle which I had become accustomed to.

Glancing through the lenses of a five-year-old girl who felt uprooted, confused and afraid about all the sudden changes, this paper reflects on the experiences of Zimbabwean children and youth who, together with their parents have joined the 'crisis-driven' migration train into almost all corners of the globe (Crush \& Tevera 2010). Another set of lenses from which this paper is written is that of my only son Tadiwanashe, who at the age of four years also experienced the tidal wave of migrating with his parents from his motherland, Zimbabwe to South Africa. I reflect on his adjustment challenges, the strides he made whilst in South Africa until the age of thirteen when his parents were once again bitten by another 'migration bug', leading the family to the United States of America (USA). As if that was not enough for Tadiwanashe, within a year of having settled in his long-cherished dreamland, the USA, another whirlwind hit home. In response to an urgent family crisis in the motherland, his parents had to make one of the most difficult decisions, waving goodbye to Tadiwanashe and leaving him behind to pursue a better education as they headed back to Zimbabwe. Whilst he remained under the capable and loving care of family friends who have since become his beloved second set of parents, one cannot begin to fathom how he felt at the age of 14 when he bade farewell to dearest mother and father at San Francisco International Airport. Tadiwanashe is 21 years old now, he has been in 
boarding school for most of his high school years and has since moved into college residence. During school breaks, especially the long summer breaks, he splits the time between his second set of parents and his biological family in Zimbabwe. Whilst Tadiwanashe dearly loves, cherishes and sorely misses his motherland, having only lived there for the first four years of his life, truly, his realities have been shaped by the seventeen years he has lived outside Zimbabwe. It is mainly from Tadiwanashe's life experiences of having migrated with his parents as an only child and from the experiences of other children who migrated from Zimbabwe, Malawi, Zambia and Ghana either into South Africa or to other parts of the global village that this article seeks to interrogate their struggles to adjust in the host country, their survival strategies, the lessons they have learnt as well as the challenges of wrestling with a sense of feeling detached or disconnected from their land of origin. Below, the article proceeds to take us down the migrant children's memory lanes.

\section{Transitioning in a Foreign Land: Interrupted and Reconstructed Childhoods}

Although the prospect of migrating, especially in search of greener pastures kindles a sense of adventure and optimism for the future, for most people, not long after migrating to a foreign land do they realise that the process is 'inherently characterized by rupture - a break, change, distance and division' in their routine (Boehm et al. 2011: 1). Whilst it is common knowledge that children are endowed with the capacity to adapt, it also needs to be acknowledged that some of the changes wrought by migration exert massive pressure on the young person's mind. Upon arrival in South Africa, one of the life-changing realities that Tadiwanashe had to contend with was the sudden realisation that absolutely no-one at the Pre-Primary School he was enrolled in could speak or understand his mother tongue, Shona. In Tadiwanashe's own words:

As a little boy, I had always been thrilled with the adventure of migrating with my parents to a faraway land. I used to nag my parents with the request to go and explore the world that I saw in pictures from my bedtime story books and on TV. My parents constantly urged me to make all the effort to master the English language from an early age since this would be the mode of communication when we eventually 
migrated. Even before enrolling at kindergarten in Zimbabwe, my parents had already introduced me to basic English vocabulary at home. However, I also had the luxury of switching to Shona both at home and in kindergarten whenever I felt that I was running short of the appropriate English terms to express myself. When we finally migrated to South Africa at the age of four, on the first day that my parents dropped me off at the Pre-Primary School, it suddenly hit home that I had to adjust to expressing myself solely in English. Although at this Pre-Primary School there were three other children whose parents were originally from Zimbabwe, however, they had all been born in South Africa and were not conversant in Shona at all. The first few weeks were a real challenge for me because I often battled to express myself to the teachers in fluent English. One experience that stood out for me during my early days at this Pre-Primary School was when I vomited after having eaten a meal that upset my stomach. When the teacher asked me what was wrong, I could not find the appropriate words to express myself and so I just shrugged my shoulders. When my parents came to fetch me at the end of the day, the teacher reported the incident to them. Upon reaching our apartment, I reverted to Shona and explained to my parents that the reason why I had vomited was because I could not tolerate the combination of samp and maas (fermented milk). Since then, my parents negotiated with the teachers that on the days when that meal was being served, my parents would provide an alternative hot meal for me.

Whilst the narration of the above incident might sound very trivial for an adult, in the eyes of a four-year-old boy, this was a serious incident. A language barrier can be very frustrating, one feels trapped and helpless, knowing what you want to say but failing to find the appropriate vocabulary to express oneself often makes one feel alienated and bewildered. Focusing on the experiences of refugee children, Dryden-Peterson (2015) also illustrates how the language barrier can become a major hindrance to the educational process, especially if it has not been properly addressed. An almost similar incident to the one discussed above which Tadiwanashe shared was his first encounter with another new child whose parents had also recently migrated from Zimbabwe and she was also enrolled at the same Pre-Primary School. He put it across as follows: 
When Nyasha ${ }^{1}$ first joined the same Pre-Primary School where I was, I had already settled in since I had been there for about three months. At first Nyasha was excited to find a whole bunch of children around her age to play with. However, as the day progressed and the other kids started being fetched to go home with their parents, Nyasha began to feel anxious that if her parents did not come to pick her up, she would not be able to find her way home. Suddenly, she started crying and the teachers tried their best to comfort her but she was inconsolable. Since the teachers knew that both Nyasha and I were Shona speaking, they then asked me to talk to her in Shona and to reassure her that she was in safe hands as well as emphasising to her that her parents were certainly coming to fetch her later. As soon as I spoke to Nyasha in Shona, her fears and concerns were resolved and she calmed down.

When Nyasha's parents heard about this incident from the teachers, they made an effort to contact us as Tadiwanashe's parents and when we eventually met them, they expressed their profound gratitude for the role played by Tadiwanashe in consoling Nyasha during her time of distress. We soon became close family friends and would often joke about how Nyasha would not calm down until she had been addressed in Shona. Nyasha's experience serves to illustrate the soothing and therapeutic power of language. It is not only children but adults who also feel much more comfortable and secure when they express their deepest fears, hopes and aspirations in their mother tongue.

As if adapting in Pre-Primary School was not bewildering enough, another perplexity which Tadiwanashe grappled to come to terms with, was the complete change of setting in the Seventh Day Adventist (SDA) congregation which we joined when we migrated to Pietermaritzburg, South Africa. Back in Zimbabwe, we used to worship in an SDA congregation where the order of service and all activities were conducted in Shona. Actually, there were no white people in our congregation back in Zimbabwe

\footnotetext{
${ }^{1}$ Not real name. Except for Tadiwanashe whose identity cannot be concealed for the obvious reason that he is my only child, pseudonyms will be used to refer to all other individuals mentioned in this article in order to protect their privacy and ensure confidentiality.
} 
since the church was located in a residential area for black people. However, since we were not conversant with the local South African language, isiZulu which is the mode of communication used in the congregations frequented by the black South Africans in KwaZulu-Natal, we therefore resorted to joining an English-speaking congregation which had predominantly white members. Tadiwanashe describes this unanticipated experience in the following words:

I had gotten very excited about going to church this time around, mainly because whilst back in Zimbabwe we used to walk a very short distance to and from church, however, my mum explained that our new place of worship was not within walking distance so we were going to hire a taxi which would take us to and from church. Being a fan of riding in a car, especially a hired taxi where we would not be squashed with other passengers, this was music to my ears. What mum did not prepare me for was how completely different the church setting would be. Hence, my first experience at our new place of worship was overwhelming to say the least. To begin with, I had never seen so many white people gathered in one place. Arriving at church, I suddenly realised that as black people, we were a tiny minority, the majority were white people. I immediately made up my mind that I was going to cling to my mum's side, lest I got lost amidst the maze of white people at church. Even though back in Zimbabwe I had reached a stage whereby I could attend 'children's church'2 all by myself and my mum would go to attend the adults' Sabbath class [service], this arrangement suddenly changed on this day. When the time came for us to separate into our respective classes, I nervously whispered to my mum that unless she accompanied me and stayed with me in my class, I wasn't going to that class alone. Fortunately, my mum conceded to my plea and she accompanied me. I was super excited when my mum was eventually appointed as one of the teachers in my [children's church] class.

${ }^{2}$ Like in most Christian denominations, in the Seventh Day Adventist Church, there is a point when members are separated into different groups according to age so that they can study scriptures and themes that are relevant to their maturity. 


\section{Sophia Chirongoma}

The above excerpt reveals the adjustment challenges that some children may deal with due to migratory patterns which expose them to foreign settings. For Tadiwanashe, his initial experience at the new Seventh Day Adventist Church in Pietermaritzburg, South Africa was an anti-climax. The sudden change in the setting caused him anxiety to such an extent that even though he used to be an independent child at church back in Zimbabwe, he regressed and turned into a clingy child because he needed his mother's reassurance. It actually took him two years to adjust and start attending children's church without being accompanied. As time progressed, he made friends at church and began to feel comfortable around the church. We became regular members of that congregation for the eight years we lived in Pietermaritzburg, such that Tadiwanashe still has fond childhood memories of this Seventh Day Adventist congregation.

Another major hurdle which Tadiwanashe encountered was the transition from pre-primary school to primary school. Having comfortably adjusted to the routine at the pre-primary school where there was a facility for day care until $5 \mathrm{pm}$ when his parents fetched him to go home, the primary school schedule was only for half a day. Since both his parents were working full-time and there was no one else at home to look after him, this meant having to shuttle from school every afternoon to the day care facility. Being in grade one made him feel like a really big boy such that he never understood why his parents insisted that for security reasons, together with his best friend, they could not walk across unaccompanied for a few metres from their primary school to the day care facility where they would spend the rest of the day. In his own words, Tadiwanashe expresses this paradoxical situation as follows:

I could not fathom why our parents insisted that we must use a shuttle service which would fetch us daily from school to our day care facility. What I resented most about this shuttle is the fact that it rarely arrived on time, this meant having to wait for it at our pick-up point which we felt was an unnecessary waste of our playtime. Whenever I tried to reason with my parents that my best friend and I can easily find our way from school to the day care facility, they always cautioned that due to the high rate of crime and numerous cases of child abductions in South Africa, it was too risky for us to do so. In my small sevenyear-old mind, I could not understand how it was possible that back in Zimbabwe, from the age of three, I was already walking unaccom- 
panied to and from kindergarten and paradoxically, at the age of seven I was being restricted from freedom of movement in South Africa.

The tight security measures which parents have to impose on their children upon migrating from Zimbabwe to South Africa is a point of contention which was raised by several adolescents and youth who participated in this study. Some of them bemoaned how their parents were so protective such that they would not allow their children to walk across to the nearest shopping mall or to travel to town unaccompanied. They felt that their freedom was being infringed upon and resented feeling 'caged' by their parents. Another common adjustment experience shared by the numerous migrant children who participated in this study was the abrupt changes in their domestic arrangements. One of the adolescents bore out his soul in the following words:

For as long as I could remember, my parents used to hire a live-in domestic helper who was responsible for most of the domestic chores. This came to an unforeseen end when we migrated to South Africa. I was only eight when my family moved from Zimbabwe to Pietermaritzburg. No sooner had we settled here, did my parents start lecturing me on the need for me to assist with household chores. I was also expected to assist my mum to look after my younger sister who was an infant then. Most of the times, when I felt like going outside to play with the other children, I would be assigned errands around the house. At first, I would protest and tell my parents that this was the domestic helper's responsibility. They would however patiently take their time to explain that we could not afford to hire domestic help since we needed to save up some money for investing back in Zimbabwe, as well as remitting some of the money for the sustenance of the extended family back home. The more I listened to my parents' rhetoric, the more I gradually resigned to my fate.

The sentiments raised in the above extract resonate with the observations made by Lam and Yeoh (2019: 1-2) who made the following remarks, 'Childhood is socially constructed and fundamentally different from adulthood, continually varying (and evolving) across time, space/place, context, class, gender and cultures'. Based on a case study they conducted in 
Romania, Botezat and Pfeiffer (2014) discussed the impact of parents' migration on the well-being of the children left behind. The uniqueness of the present study is that it focuses on presenting the migrant children's experiences as a lens through which to illustrate varied ways in which the process of migration either interrupted or reconstructed their lived realities as they transitioned from their original home country to the host country. Having outlined some of the adjustment challenges encountered by migrant children, below the article proceeds to discuss some of the common coping strategies adopted by the migrant children as they navigate their host countries.

\section{Coping/ Survival Strategies in the Host Country}

Although there is a lacuna in scholarly literature which explores the children's experiences, particularly their views regarding parental migration within the Southern African context, scholars such as Huang and Yeoh (2011: 394) writing within the Asian context, have reiterated the need to 'highlight and understand children's agency, resilience and creativity in navigating parental migration'. The same point is restated by Lam and Yeoh (2019: 1) who, informed by a case study they conducted among the 'left-behind' children in Indonesia and the Philippines, came to the conclusion that 'the experiences, feelings and reactions of children affected by migration are often hidden within a predominantly adult-centric literature on migration despite the fact that children are often situated at the heart of migration decisions made largely for their sakes'. If providing for children's needs is usually the driving force behind migration decisions, it is therefore pertinent that considerable research be dedicated towards understanding their stance on migration. It is also equally important that we explore their survival strategies in the event that they accompany their parents on the migratory path, as was Tadiwanashe's experience. A common existential challenge which several migrant children and youth shared, one which they have had to develop mechanisms for dealing with, is the death of a loved one in their motherland and how to cope with their grief, being so far away from home. One youth who migrated from Zimbabwe to join her parents in Canada shared her experience of bereavement and how she had to lean on what they call 'cyber mourning' that is, using technology to connect with the family in the motherland and indirectly participating in the death and mourning rituals via cyberspace. Below she emotionally unpacks her experiences: 
Barely two weeks after joining my family in Canada in June 2013, my maternal grandmother fell ill, was rushed to the hospital in Harare, Zimbabwe and within an agonising period of three days, she had passed on. I received the news of my grandmother's passing whilst I was making frantic efforts to assist my mother with securing the earliest and shortest flight schedule for travelling back to Zimbabwe. Seeing the panicky state my mother was already in due to her mother's critically ill condition, I knew that it would not do her any good to unnerve her further by disclosing that grandmother had already passed on. As such, I had to put up a brave face whenever I was around my mother. Whilst my mother was busy finalising her packing for the trip, I would sometimes go upstairs to exchange phone calls with the family back in Zimbabwe and cry my heart out. I maintained regular contact with the family during the mourning period, I would exchange video calls with family members and I managed to follow the funeral proceedings via Skype and video conferencing. Whilst I was yearning to be physically around the family during this trying time, the connection via cyber space helped me so much in processing the grief.

The above emotionally packed excerpt reveals how the use of technology has helped the migrant children and youth to deal with some of life's travails. Some of the study participants also shared how they make use of WhatsApp video calls, Facebook live streaming, Skype and viewing a video recording of the funeral proceedings for their loved ones to help them in processing the grief. Like in most African cultures, the Shona people in Zimbabwe perceive death and mourning rituals as a communal undertaking (Chitando 1999). Hence, failing to attend the funeral of a close family member denies the bereaved person a sense of closure (Kamwendo \& Manyeruke 2017). Participating in the death and burial rituals also accords the bereaved some space to undergo a therapeutic healing process (Mwandayi 2011). Losing a loved one through death deeply touches all human souls, regardless of age, hence, it is important for scholarly research to also focus on how migrant children and youth are tapping into modern technology as a mechanism for coping with grief. The above-mentioned migrant youth who shared her experience of leaning on connections through cyberspace to deal with her grandmother's untimely passing also tearfully described how five 
years down the line, in May 2018, she encountered another bereavement as a result of her male cousin's sudden death. She communicated and put it across as follows:

During my previous visit to Zimbabwe, I had the privilege to bond with and spend real quality time with my cousins, including my youngest cousin brother [male cousin] whom I got to meet in person for the first time. Little did I know that when he bade me farewell at the airport in Harare on my return trip to Canada, it was going to be the last time to see him alive. Nothing ever prepared me for receiving the most shattering news informing me that this beloved four-year-old cousin brother [male cousin] of mine had succumbed to an undetected infection and died a few hours after having been admitted in [to] a Zimbabwean hospital. Since I had just started a new job, it was practically impossible for me to take time off from work and travel to Zimbabwe to attend the funeral. In the same manner that I had utilised technology during my grandmother's funeral, once again, I resorted to the same facility to grieve with the family back in Zimbabwe. On the day my cousin brother [male cousin] was being buried, I took the day off from work and followed all the funeral proceedings via WhatsApp video calling. My heart was torn into pieces as I witnessed my dearly loved little cousin being laid in his final resting place.

The heart-breaking experiences of grief chronicled above help to illuminate some of the numerous struggles endured and survival strategies adopted by migrant children and youth as they exercise their agency to deal with life's crisis moments. Being separated from family through space and time has stirred them into action, they have adopted survival strategies to maintain strong links with their families during moments of both happiness and sadness. Some of the migrant children and youth also shared how they have tapped into technology to allow them to participate in important family events such as weddings, birthday and graduation parties, albeit virtually. Missing out on these important family events was a recurring challenge mentioned by the migrant children and youth who participated in this study. However, not being able to attend the funeral of their loved ones stood out as the most painful experiences for the study participants. Their experiences of bereavement in a faraway land affirm the observations on the Shona people's views on death made by 
Chitando (1999) and affirmed by Kamwendo and Manyeruke, (2017: 151) who stated that 'funerals stand out as major community gatherings, and one could be struck by the energy and enthusiasm of the participants as they dance, talk and sing'.

Another coping mechanism utilised by the migrant children and youth in times of bereavement and grief is to memorialise the happy and cherished memories of their loved ones through creating family albums online where they post pictures, videos and memoirs of the deceased. Such a coping mechanism was described by Tadiwanashe as follows:

My first real encounter with bereavement and grief was at the age [of] four when my paternal grandmother passed on, just a few weeks after we had migrated to South Africa. Due to logistical challenges, my mother could not travel back to Zimbabwe for the funeral. I would often accompany my mother to the nearby public telephone booth where she made numerous phone calls to Zimbabwe. What struck me then is that she sobbed bitterly as she spoke on the phone. My little mind's understanding of death then was based on the Christian teaching that death is a peaceful and painless sleep as one awaits to be resurrected by Jesus on the resurrection morning. I would therefore question why my mum was crying when my grandmother was simply sleeping whilst waiting for the glorious resurrection. As a result, I spent time drawing pictures illustrating my imagination of what would happen to my paternal grandmother on the resurrection morning. Doing that comforted me and helped me to cope with her passing. Fast forwarding to the passing of my maternal grandfather four years later, I was eight years old then and it so happened that he passed on whilst we were in Zimbabwe for the festive holiday. This availed an opportunity for me to attend a funeral for the first time in my life. Witnessing the outpouring of grief from all the adults and young people who attended the funeral gave me a different perspective about death. When we travelled back to South Africa, I spent time on the computer writing down reflections about the events during grandpa's funeral and I also chronicled most of my fond memories about him. I also compiled pictures of him and saved them in a computer file. Six years later [June 2013], I attended my maternal grandmother's funeral. She passed on during my first visit to Zimbabwe after having recently 
migrated from South Africa to the United States of America. I was fourteen then, hence, the sombre and tearful mood at the funeral deeply impacted me. When I returned to school after the summer break, whenever we were assigned to write an essay in my creative writing class, my essays revolved around the fond memories about the activities we used to do with my grandma, the stories she told us, as well as her numerous gestures of love. Whilst the passing of both my grandmas and my maternal grandpa left a gaping void in my life, nothing can ever adequately describe the utter shock and grief that gripped me when in May 2018, my sobbing and grief-stricken mum phoned to inform me that my dearest four year old cousin brother [male cousin] had died. I was pained to the core because he was like the younger blood brother I never had, we shared an unexplainably profound bond. Since it was in the middle of the school term, it was practically impossible for me to attend the funeral. I mourned with the family via video calls, contributed towards selecting the pictures which would be displayed on his casket and spent time on my computer chronicling such a budding flower taken prematurely. I continue talking about his escapades whenever I get a chance to talk to my family over the phone.

The coping mechanisms described in a very detailed manner in the above excerpts provide a glimpse into the emotional turmoil caused by bereavement and grief experienced by the migrant children and youth. The above extracts also clearly illustrate that instead of succumbing to depression or wishing their emotions away, the migrant children and youth have been innovative in creating pathways to process their emotions. Whilst there are numerous examples of migrant children and youth who have either succumbed to depression, anxiety attacks and some have resorted to substance abuse as a result of failing to cope with their stress and challenges related to their immigrant status, this is beyond this article's purview. The focus of this article is on the creative and positive survival strategies adopted by migrant children and youth.

Having discussed their numerous survival strategies, the next section turns to reflect on how the process of migration presents a barrier between the realities in their original home country and their daily experiences as children or youth living in a foreign country. 


\section{Disconnected from most of the Zimbabwean Realities}

Having migrated to the diaspora at a young age, most of the migrant children and youth tend to suffer from an identity crisis. Growing up being detached from the kinship ties which are the general norm in Southern Africa often presents challenges for them when they are expected to conform to certain norms and values which tend to contradict the cultural script which they are familiar with in the diaspora. This predicament was succinctly captured by one such youth who expressed it as follows:

My parents migrated from Zimbabwe to New Zealand seventeen years ago, my older sister was four and I was a two year old girl. Whilst I taught myself to read and write Shona, my sister can only speak but she cannot write Shona. However, even my ability to read and write my mother tongue does not make it any better for me to understand some of the Shona cultural norms and values. For instance, whenever we visit my grandparents' rural home, our mother, aunties and uncles often caution us that we cannot walk around the village dressed in short skirts or revealing tops. Also, whenever we wear shorts, they advise us to wrap a cloth around our bodies. I often quarrel with my mum, protesting that imposing such restrictions on me is tantamount to body shaming and an infringement of my rights. My aunties and grandma have also made efforts to explain to my sister and I that whenever we visit the village, it is important for us to respect the community's norms and values but I still struggle to make sense of these values. In my worldview, all this sounds archaic, although slowly I am learning to embrace the culture.

The issues raised by a nineteen year old girl quoted above reflect the complexities encountered by several migrant children and youth especially as they must find ways of reconciling two conflicting world views. Some of the migrant children and youth who participated in this study expressed a sense of frustration, when members of their extended family describe them as disrespectful due to certain tendencies they exhibit during the short visits to their original home country. Others also felt that they had been stripped of their sense of belonging due to having lived in the diaspora for an extended period. They bemoaned that sometimes their Shona is not fluent and when they speak 


\section{Sophia Chirongoma}

with a different accent they feel alienated when some members of the extended family call them makaradhi (coloured/ people of mixed heritage) or varungu/varumbi (white people) which denotes that they are no longer considered as original members of the family. As Moyo (2017: 15) puts it succinctly, the migrant children and youth often 'find themselves in a luminal state, not fully accepted in their host countries, but also castaways in the land of their parents ... and are often spectators of 'their' own culture'.

Another aspect that perpetuates their sense of being disconnected is the manner in which living with their parents in the diaspora robs them of the opportunity to grow up in the communal web of existence. Whereas in most African communities, members of the extended family exist in a mixed web of interrelatedness, unfortunately, for most African families living in the diaspora they operate as an individualistic family unit. The old adage, 'it takes a village to raise a child' comes to mind here and regrettably, most migrant children and youth are bereft of this privilege. One of the young men whose parents migrated from Malawi to South Africa before he was even born expressed his predicament as follows:

We lived as a single family unit until I was five years old. Since then, our home has hosted so many members of the extended family such that I have lost count of people who have passed through our home. Some stay for a short period whilst seeking employment, then they move out. Others stay longer, especially cousins who come to study at the university where my parents are working. I resent their encroachment of my space, I often have to share my bedroom space with members of the extended family. What is worse is that sometimes when I want to watch my favourite TV program, I am told that the adults want to watch either the news or sports channel. My parents often tell me that in our culture, my cousins are considered as my brothers and sisters. I don't get it, I am an only child and I long for my private space without all these intruders.

The concerns raised by the young man cited above reflects some of the common struggles shared by several migrant children and youth. Due to having been exposed to a different culture in their host countries, they find it difficult to conceptualise the African communal web of existence which is the norm in their country of origin. Another sense of disconnectedness and up-rootedness 
experienced by several migrant children and youth pertains to how on one hand they have nostalgia about relocating to their home countries but on the other hand, the stark socio-economic realities between their host countries and their motherland renders that dream far-fetched. The following extract from Tadiwanashe sums this up aptly:

I feel more at home whenever I am spending time with my family in Zimbabwe. I miss home and I really cherish every moment I spend in my home country during my occasional visits. Zimbabwe will always be dear to me. However, the prevailing social, economic conditions and the political stalemate in my home country has shattered my dreams of ever being able to settle down for a career in Zimbabwe. My gut tells me that I will not be able to cope in this capricious environment. Having lived and attained my education in South Africa and in the United States of America made me realise that my identity as a foreigner will always present a barrier to some of my aspirations outside my home country. In spite of the various obstacles that my foreign nationality might present in my future career pursuits, I feel that I have no other option but to trudge ahead in a foreign country.

The sentiments raised in the above extract unravel the common struggles faced by several migrant children and youth. They feel as if they are 'trapped between a rock and a hard place'. Whilst they do not feel completely at home in their host country, regrettably, the status quo in their country of origin is not conducive to allowing them to return to live a safe and prosperous life. This leaves them literally floating, as the title of the paper denotes, they are left in limbo because they are 'neither here nor there'. They have 'tasted the good life' in their host countries, on one hand, the prospects of living in a land faraway with a better future draws them further away from their country of origin. On the other hand, they lack the sense of belonging shared by those who have remained in their motherland. On this note, below, the discussion of this paper draws to a close.

\section{Conclusion}

The main focus of this article has been to add another chord to the numerous voices advocating for the need to pay attention to the experiences of migrant 
children and youth so that we can learn from them. Their adjustment challenges, for instance battling with the language barrier, reconfiguring their childhood experiences and having to contend with an identity crisis have been noted. Echoing the observations made by Lam and Yeoh (2019) in their case study conducted in Asia, the article also acknowledged that instead of becoming passing victims who wallow in the maze of challenges wrought by the process of migration, the migrant children and youth have exercised their agency through adopting numerous survival strategies. For instance, they utilise technology to maintain ties with family in their land of origin, which makes it possible for them to share both happy and sad communal moments. The resilience, tenacity and self-reliance developed by the migrant children and youth as they navigate their new terrain is testimony to the fact that migration is not always fraught with negative effects. Hopefully, the voices of migrant children and youth presented in this article will capture the attention of policy makers in Southern Africa and influence them to implement migration policies which pay particular attention to the needs of migrant children and youth. It is also hoped that these same voices will serve as the voice of the numerous voiceless migrant children and youth whose parents, driven by the quest to provide a better life (materially) for their children, pursue the migratory path and in doing so, neglect their children's emotional needs. Although written in a slightly different context from the foregoing discussion, it seems befitting to conclude this discussion with the following citation:

Leaving the comfort of your home, being uprooted from all your loved ones and from all that is familiar, and venturing into the unknown: such an experience can only be adequately fathomed by one who has travelled that path (Chirongoma 2012: 119).

\section{References}

Boehm, D.A., J.M. Hess, C. Coe, H. Rae-Espinoza \& R.R. Reynolds 2011. Introduction: Children, Youth and the Everyday Ruptures of Migration. In Coe, C., R.R. Reynolds, D.A. Boehm, J.M. Hess \& H. Rae-Espinoza (eds.): Everyday Ruptures: Children, Youth, and Migration in Global Perspective. Nashville: Vanderbilt University Press.

https://doi.org/10.2307/j.ctv16f6hv3.4

PMid:27536421 PMCid:PMC4980731 
Botezat, A. \& F. Pfeiffer 2014. The Impact of Parents Migration on the Wellbeing of Children Left Behind: Initial Evidence from Romania. IZA Discussion Paper No. 8225. https://doi.org/10.2139/ssrn.2432946

Chirongoma, S. 2012. In Search of a Sanctuary: Zimbabwean Migrants in South Africa. In Carpenter, J. (ed.): Walking Together: Christian Thinking and Public Life in South Africa. Texas: ACU Press.

Chitando, E. 1999. Deathly Concern: African Christians and Cremation in Zimbabwe. Missionalia 27:1, 10 - 19.

Crush, J. \& D. Tevera 2010. Exiting Zimbabwe. In Crush, J. \& D. Tevera (eds.): Zimbabwe's Exodus: Crisis, Migration, Survival. Cape Town: Southern African Migration Programme

Dryden-Peterson, S. 2015. The Educational Experiences of Refugee Children in Countries of First Asylum. Washington, DC: Migration Policy Institute. Huang, S. \& B.S.A. Yeoh 2011. Navigating the Terrains of Transnational Education: Children of Chinese 'Study Mothers' in Singapore. Geoforum: Journal of Physical, Human, and Regional Geosciences 42,3: 394 - 403. https://doi.org/10.1016/j.geoforum.2011.01.010

Hoang, L.A., T. Lam, B.S.A. Yeoh \& E. Graham 2015. Transnational Migration, Changing Care Arrangements and Left-Behind Children's Responses in Southeast Asia. Children's Geographies 13,3: 263 - 277. https://doi.org/10.1080/14733285.2015.972653

PMid:27134570 PMCid:PMC4837485

Kamwendo, L.M. \& C. Manyeruke 2017. Power Politics During and After Funerals amidst the Shona of Zimbabwe. Africology: The Journal of Pan African Studies 10,2: 151 - 164.

Lam, T. \& B.S.A. Yeoh 2019. Parental Migration and Disruptions in Everyday Life: Reactions of Left-behind Children in Southeast Asia. Journal of Ethnic and Migration Studies.

https://doi.org/10.1080/1369183X.2018.1547022

PMid:31827371 PMCid:PMC6874285

Mafukidze, J. 2006. A Discussion of Migration and Migration Patterns in Africa. In Cross, C., D. Gelderblom, N. Roux \& J. Mafukidze (eds.): Migration in Sub-Saharan Africa: Proceedings of an African Migration Alliance Workshop. Cape Town: HSRC Press.

Manik, S. 2012. Zimbabwean Education Professionals in South Africa: Motives for Migration. In Penson, J. \& A. Yonemura (eds.): The Next Step in Managing Teacher Migration: Papers of the Sixth Commonwealth 
Research Symposium on Teacher Mobility, Recruitment and Migration. London: UNESCO.

Maphosa, F. 2007. Remittances and Development: The Impact of Migration to

South Africa on Rural livelihoods in Southern Zimbabwe. Development

Southern Africa 21,1: 123 - 135.

https://doi.org/10.1080/03768350601165942

Moyo, H. 2014. Dual Observances of African Traditional Religion and

Christianity: Some Implications for Pastoral Care in the Pluralistic

Religious Worldview of the Ndebele People of Matabo in Zimbabwe.

Journal of Theology for Southern Africa Number 148,March: 115 - 132.

Moyo, H. 2015. Pastoral Care in the Healing of Moral Injury: A Case of the Zimbabwe National Liberation War Veterans. HTS Teologiese Studies/

Theological Studies 71,2:Art. \#2919, 11 pages.

http://dx.doi.org/10.4102/hts.v71i2.2919

Moyo, M. 2017. The Zimbabwean Crisis and the Family: Challenges and

Opportunities for the Zimbabwean Church. Zimbabwe Journal of

Theology and Religious Studies 1,1: 8 - 21. Harare: Africa Institute for

Culture, Peace, Dialogue \& Tolerance.

Mwandayi, C. 2011. Death and After-life Rituals in the Eyes of the Shona:

Dialogue with Shona Customs in the Quest for Authentic Inculturation. Bamberg: University of Bamberg Press.

Dr. Sophia Chirongoma

Senior Lecturer Religious Studies Department

Midlands State University Zimbabwe sochirongoma@gmail.com or sochirongoma@yahoo.com

Dr. Sophia Chirongoma Academic Associate/ Research Fellow Research Institute for Theology and Religion (RITR)

College of Human Sciences University of South Africa (UNISA) sochirongoma@gmail.com or sochirongoma@yahoo.com 